\title{
DIABNOR - a register study of medical quality in diabetes health care
}

\author{
Geir Joner \\ Department of Pediatrics, Women and Children's division, Oslo University Hospital and \\ Department of Health Management and Health Economy, Institute of Health and Society, University of Oslo, Oslo, Norway \\ geir.joner@medisin.uio.no
}

\section{SUMMARY}

\begin{abstract}
The purpose of creating the DIABNOR register is to study the quality of diabetes care in Norway. We will study the prevalence of serious complications ("hard endpoints") and what kind of treatment patients receive and how these vary with age, gender, ethnicity, education and place of residence. It is a crosssectional study based on data from all hospital contacts in Norway between 2004 and 2010, linked to the National Prescription Database (NorPD) containing information on all drug treatment patients receive, not only from hospitals but also from general practitioners. Data are also linked to Statistics Norway for collecting information about ethnicity, social status and marital status. Development of quality indicators (QI) for diabetes is also an objective of the project, including indicators to measure compliance with guidelines and achievement of treatment goals. The researchers behind the project believe it is important to measure quality and differences in health care in order to improve the prognosis in this patient group.
\end{abstract}

\section{BACKGROUND}

There are reasons to believe that the quality of diabetes care in Norway is generally good and equivalent to other European countries, based on rough measures and some studies indicating that outcome measured as hard endpoints is improving (1-3). A few studies are showing that achievement of treatment goals in general practice is low $(4,5)$, and there is a gap between guidelines and practice in the treatment of type 2 diabetes (6), but there are no broad national surveys or quality registers as basis for a general perception about quality in care. Some particularly important questions are whether the quality of treatment and the results vary with gender, ethnicity, social status and where you live in the country.

The DIABNOR project is a collaboration between the Norwegian Knowledge Centre for the Health Services (NOKC), Women and Children's division, Oslo University Hospital (OUS) and Institute of Health and Society, University of Oslo (UiO). The project aims to collect a large dataset from all Norwegian hospitals, obtained with a routine data collection client (the FS system) (7), and link the data to the databases of Statistics Norway, to the central population register and to the National Prescription Database (NorPD). In addition to research on quality aspects of diabetes treatment and care, there is a need for developing and publishing quality indicators for health services provided to people with diabetes. The Nordic Council has initiated work in this area leading to a report giving recommendations for several groups of diseases including diabetes (8). Internationally proposed diabetes quality indicators are showed in Table 1.

\section{OBJECTIVES}

The aims of DIABNOR are to study the prevalence of complications and mortality of diabetes in Norway and drug therapy in a nationwide hospital material for the period 2004-2010 and if the quality of treatment as measured on these parameters vary with age, gender, ethnicity, social status and residency. The structure is shown in Figure 1.

1. To study the prevalence of diabetes complications, morbidity and death

a. prevalence of diabetes complications, morbidity and death by age, gender, ethnicity, education and place of residence

b. causes of death and variety of these in relation to age, gender, ethnicity, education and health region.

c. time trends in complications and mortality and changes in the distribution of causes of death

2. To study the social and geographical variation in the use of specialist health care

a. use of specialized health care / medical services in relation to age, gender, ethnicity, education and place of residence

b. pharmacological treatment of diabetes mellitus and variations in the use of different treatment combinations in relation to age, gender, ethnicity, education and place of residence

3. To test the appropriateness of the data set (validity/ reliability) to develop evidence-based quality indicators in the diabetes area (established or new, single or compound)

\section{MATERIAL AND METHODS}

The study is based on medical and administrative data from all hospital admissions in Norway between 2004 and 2010 (outpatient clinics, day care and wards), about 1.3 million contacts with patients with diabetes mellitus as primary or secondary diagnosis or diabetesrelated diagnoses and procedures (such as diabetic nephropathy + ESRD + dialysis). Complications are 


\section{DiabNor - Overview}

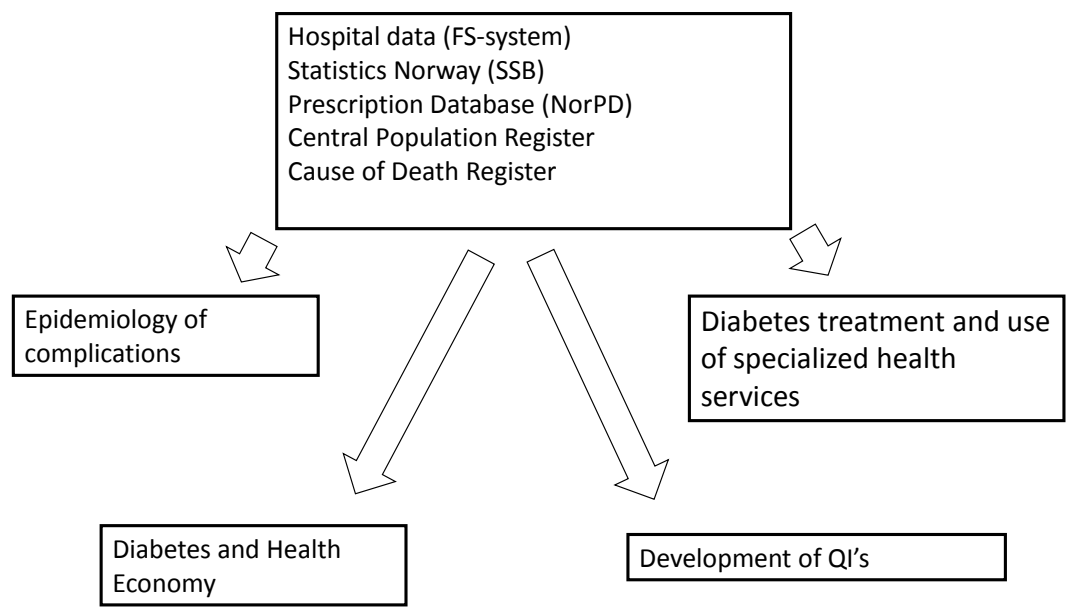

Figure 1. Overview of the DIABNOR research project.

Table 1. Proposed Quality indicators (QI's) in diabetes.

\begin{tabular}{|c|c|c|c|c|c|c|}
\hline & $\begin{array}{l}\text { Norwegian } \\
\text { Medical } \\
\text { Association }\end{array}$ & $\begin{array}{l}\text { Nordic } \\
\text { Council of } \\
\text { Ministers }\end{array}$ & OECD & WHO & Denmark & Sweden \\
\hline HbA1c within goal (\%) & $\mathrm{X}$ & $\mathrm{X}$ & $\mathrm{X}$ & & & $\mathrm{X}$ \\
\hline Blood pressure within goal (\%) & & & & & & $\mathrm{X}$ \\
\hline Insulin shock (\%) & $\mathrm{X}$ & & & & & \\
\hline Readmission (unplanned hospitalization) & & $\mathrm{X}$ & & $\mathrm{X}$ & & \\
\hline Amputation, lower extremity (rate) & & $\mathrm{X}$ & $\mathrm{X}$ & & & \\
\hline \multicolumn{7}{|l|}{ Proportion of diabetes patients treated with } \\
\hline - antihypertensive & & & & & & $\mathrm{X}$ \\
\hline - ACE inhibitors & & & & & & $\mathrm{X}$ \\
\hline - angiotensin-II-ant. & & & & & & $\mathrm{X}$ \\
\hline - lipid lowering drugs & & & & & & $\mathrm{X}$ \\
\hline
\end{tabular}

measured as "hard endpoints" as dialysis treatment, laser treatment of eyes, acute heart disease (AMI) and stroke in patients with a diabetes diagnosis. When calculating the prevalence of complications, only conditions exclusively treated in hospitals are included. The number of people with diabetes per health region is unknown, but we assume that the proportion of persons with diabetes mellitus are the same in all health regions, based on user rates of antidiabetic drugs in NorPD. We will also study the variation in time and time trend of mortality and causes of death based on the Central Population Register (register status: alive and living in Norway, emigrated or deceased) + Cause of Death Register (causes of death). The project will investigate whether the chosen therapy and prognosis varies among hospitals and about ethnicity, education and place of residence are associated with choice of treatment. Hospitals datasets will be linked to census data (gender, register status, address), Statistics Norway (ethnicity, education + income) and the NorPD (all prescriptions 2004-2010 from any doctor). Deve- lopment of quality indicators (QI's) for diabetes will be started with validation of the internationally established QI's for Norwegian datasets. In addition, we use the dataset to examine the possibility of developing new CI for diabetes, single or composite. This is important to ensure that ability to measure differences in the quality of treatment including the use of guidelines in health care may improve the prognosis for patients.

Based on data from NPR 2006 (9) we have estimated the number of hospital contacts for diabetes to approx. 170000 a year. The NPR 2006-dataset was anonymized, so we do not know the number of individuals, but if the mean number of visits is two, the number represents 85000 patients which is $45-55 \%$ of known subjects with diabetes in Norway (10).

\section{RESUlts}

As of April 2013, all hospitals in Norway (about 65) have provided research data to the knowledge centre and the dataset has been linked to the databases in SSB 
including the cause of Death Register and NorPD. NOKC has several datasets from other projects (30days mortality) and test sets from the National Patient Register. Quality assurance tests based on comparing the actual data set to the "test sets" show that data quality is good and there is only one hospital that lacks complete outpatient data for the last 2 years.

\section{DISCUSSION}

The project is unique because it brings together complete clinical data for nearly all treatment of people with diabetes in Norway and therefore allows research on quality of care and the use of treatment guidelines. The project can also display the geographical and social disparities in treatment and prognosis. The material is subjects with diabetes with one or more hospital contacts in the 7-year period 2004-2010 and subjects only treated in primary care will not included. The lack of data from primary care is partly compensated by the fact that all the prescriptions from GPs to the patient in the material are included.

In Norway we have two other quality registers: Norwegian Childhood Diabetes Register (NCDR) and the Norwegian Diabetes Register for adults. These registers collect data prospectively on newly registered patients, while DIABNOR is a cross-sectional study describing the status today. NCDR publish several good process indicators, but few result indicators, and the register for adults will be able to publish QIs in the future. The registers are complementary to each other and will be able to make comparisons that indicate whether treatment outcomes are improving or not. DIABNOR-register data is anonymized for researchers and cannot be linked to other registers.

An equivalent dataset has never been available to evaluate the care of diabetes in Norway. This unique research project will provide new and important results about the status of the Norwegian diabetes care and provide answers to research questions about the prognosis of diabetes patients and the variation of treatment by age, gender, ethnicity, education and region. If the hypothesis about variation in prognosis and care is confirmed, measures may be taken to improve the treatment and care by identifying the weak leaks. The study may contribute to the improvement in the care of a widespread, severe and chronic disease.

\section{REFERENCES}

1. Skrivarhaug T, Bangstad HJ, Stene LC, Sandvik L, Hanssen KF, Joner G. Low risk of overt nephropathy after 24 yr of childhood-onset type 1 diabetes mellitus (T1DM) in Norway. Pediatr Diabetes 2006; 7 (5): 239-46.

2. Skrivarhaug T, Fosmark DS, Stene LC, Bangstad HJ, Sandvik L, Hanssen KF, et al. Low cumulative incidence of proliferative retinopathy in childhood-onset type 1 diabetes: a 24-year follow-up study. Diabetologia 2006; 49 (10): 2281-90.

3. Skrivarhaug T, Bangstad HJ, Stene LC, Sandvik L, Hanssen KF, Joner G. Long-term mortality in a nationwide cohort of childhood-onset type 1 diabetic patients in Norway. Diabetologia 2006; 49 (2): 298-305.

4. Claudi T, Cooper J, Skogoy K, Hausken MF, Melbye H. [Diabetic care in Norwegian general practice. A report of current status from Salten and some regions in Rogaland]. Tidsskr Nor Lageforen 1997; 117 (25): 3661-4.

5. Cooper JG, Claudi T, Jenum AK, Thue G, Hausken MF, Ingskog W, et al. Quality of care for patients with type 2 diabetes in primary care in Norway is improving: results of cross-sectional surveys of 33 general practices in 1995 and 2005. Diabetes Care 2009; 32 (1): 81-3.

6. Jenssen TG, Tonstad S, Claudi T, Midthjell K, Cooper J. The gap between guidelines and practice in the treatment of type 2 diabetes. A nationwide survey in Norway. Diabetes Res Clin Pract 2008; 80 (2): 314-20.

7. Tomislav Dimoski. Prosjekt: FS datainnsamling for DIABNOR. The Norwegian Knowledge Center for the Health Services (NOKC), 2013.

8. Nordisk kvalitetsmåling i sundhedsvæsenet. Report No.: 2010:572, 2010.

9. Flingtorp R, Joner G. Volum og geografisk fordeling av diabeteskomplikasjoner i 2006. Unpublished: University of Oslo, Institute of Health Adminstration and Health Economy \& Norwegian Knowledge Center for the Health Services, 2008.

10. Stene LC, Midthjell K, Jenum AK, Skeie S, Birkeland KI, Lund E, et al. [Prevalence of diabetes mellitus in Norway]. Tidsskr Nor Lageforen 2004; 124 (11): 1511-4. 